\title{
Structure Refinement Upon Ultrasonic Melt Treatment in a DC Casting Launder
}

\author{
TUNGKY SUBROTO (D), ${ }^{1,7,8}$ DMITRY G. ESKIN,${ }^{1,2}$ \\ CHRISTOPHER BECKWITH, ${ }^{3}$ IVAN SKALICKY, ${ }^{4}$ DAN ROBERTS, ${ }^{4}$ \\ IAKOVOS TZANAKIS, ${ }^{5,6}$ and KOULIS PERICLEOUS ${ }^{3}$
}

\begin{abstract}
1.--Brunel Centre for Advanced Solidification Technology (BCAST), Brunel University London, Uxbridge UB8 3PH, UK. 2.-Tomsk State University, Tomsk, Russia 634050. 3.-Computational Science and Engineering Group, University of Greenwich, 30 Park Row, London SE10 9LS, UK. 4.-Constellium UTC, Brunel University London, Uxbridge UB8 3PH, UK. 5.-Faculty of Technology, Design and Environment, Oxford Brookes University, Oxford OX33 1HX, UK. 6.-Department of Materials, University of Oxford, Oxford OX1 3PH, UK. 7.—e-mail: Tungky.subroto@brunel.ac.uk. 8.—e-mail: Tungky.subroto@gmail.com
\end{abstract}

\begin{abstract}
This work focuses on ultrasonic melt treatment (UST) in a launder upon pilotscale direct chill (DC) casting of 152-mm-diameter billets from an AA6XXX alloy with $\mathrm{Zr}$ addition. Two casting temperatures $\left(650^{\circ} \mathrm{C}\right.$ and $\left.665^{\circ} \mathrm{C}\right)$ were used to assess their effect on the resulting microstructure (grain size, particle size, and number density). Structure refinement results show the feasibility of UST in the DC casting launder. This is quantified through the corresponding reduction of grain size by around 50\% in the billet center, or more towards the billet surface, reduction of the average $\mathrm{Al}_{3} \mathrm{Zr}$ particle size, and increase in the particle number density. A higher $\mathrm{Al}_{3} \mathrm{Zr}$ particle density was obtained when the alloy was cast at $665^{\circ} \mathrm{C}$. Numerical simulation results and suggestions on how to improve the treatment quality of UST in DC casting launder are also provided.
\end{abstract}

\section{INTRODUCTION}

Direct-chill (DC) casting is a typical means of producing aluminum alloy billets suitable for further downstream processing. ${ }^{1}$ The quality and properties of the as-cast product are directly linked to its microstructure; finer structure commonly leads to superior mechanical properties, ${ }^{2}$ and better castability $^{3,4}$ and formability for subsequent processing, ${ }^{5,6}$ and decreases the severity of casting defects. $^{2}$ To refine the structure of aluminum alloys, typically $\mathrm{TiB}_{2}$ or $\mathrm{TiC}$ additions are used, ${ }^{2}$ but also individual elements such as $\mathrm{Ti}^{7}$ and $\mathrm{Zr}^{8,9}$ can produce grain refinement.

Ultrasonic melt treatment (UST) is an attractive melt treatment technology because it enables a similar or even more significant structure refinement than that achievable with common grain refining practice, but with lesser amount of additions. ${ }^{10}$ This makes UST not only economically

(Received April 23, 2020; accepted June 30, 2020;

published online July 27, 2020) appealing but also environmentally friendly. The structure refinement mechanism by UST has been comprehensively reviewed by Eskin and Eskin ${ }^{10}$ and the mechanisms can be summarized as enhanced heterogeneous nucleation through activation of latent nonmetallic inclusions (i.e., oxides) and fragmentation of primary intermetallics. 9,10 These mechanisms are profoundly dependent on the acoustic cavitation (generation and implosion of cavitation bubbles) that are formed in the melt due to high-frequency (ultrasonic) vibrations with amplitude larger than a certain threshold (Blake threshold). After an acoustic cavitation bubble is formed, it pulsates and eventually collapses, subsequently generating impact pressures which may locally reach beyond $400 \mathrm{MPa}$ for a short period of time. ${ }^{11}$ Such pressures can activate dormant inclusions by their wetting and fragment the primary intermetallics in the vicinity of the collapse. ${ }^{12}$ In the latter case, where the fragmented intermetallics represent high-potency nucleants (e.g., $\mathrm{Al}_{3} \mathrm{Ti}, \mathrm{Al}_{3} \mathrm{Zr}$, and $\mathrm{Al}_{3} \mathrm{Nb}^{13,14}$ ), these may act as nucleation points 
for $\mathrm{Al}$ grains, thus refining the structure through enhanced nucleation. The fragmentation or changed morphology of other primary intermetallics (for example, $\mathrm{Al}_{3} \mathrm{Fe}$ and $\beta$-AlFeSi) ${ }^{15}$ would be beneficial for the mechanical properties of the alloy. ${ }^{16}$

Previous research on UST of aluminum melts showed that addition of transition metals such as $\mathrm{Zr}$ and $\mathrm{Ti}$ can significantly improve the structure refinement efficiency when UST is applied in the range of primary solidification of the relevant phases. $^{9,17}$ These studies reported that, to attain good structure refinement with UST, the addition of $\mathrm{Zr}$ had to be $\geq 0.18 \%$, which is beyond its solubility limit in liquid $\mathrm{Al}(0.11 \%)$, whereas a small addition of $\mathrm{Ti}$ ( $\geq 0.015$ wt.\%) would suffice. The prescribed amount of $\mathrm{Zr}$ addition is needed for the formation of $\mathrm{Al}_{3} \mathrm{Zr}$ particles above the $\mathrm{Al}$ solid-solution formation temperature. Based on the edge-to-edge matching model, ${ }^{13,18}$ it has been shown ${ }^{8}$ that $\mathrm{Al}_{3} \mathrm{Zr}$ has an insignificant crystallographic mismatch orientation with the $\mathrm{Al}$ matrix, thus having great potential as an effective substrate for $\mathrm{Al}$ grains to nucleate and grow. While the addition of $\mathrm{Zr}$ could produce an abundant number of suitable nucleation points for $\mathrm{Al}$ grains, this element does not have a substantial growth restriction factor in $\mathrm{Al},{ }^{8,19}$ thus the addition of $\mathrm{Ti}$ is beneficial for further structure refinement. ${ }^{20}$

Although UST has been successful in both laboratory- and small-scale melt processing, the current challenge is to carry out the effective treatment of a large melt volume using a single-sonotrode source. Traditionally, this difficulty has been circumvented by employing a multi-sonotrode UST system, ${ }^{10,21,22}$ but this approach is deemed to be expensive and the setup was too complicated, thus reducing the feasibility of its industrial adoption. While there are numerous studies demonstrating the effect of ultrasound on grain refinement in $\mathrm{Al}$ alloys treated during solidification, this methodology is confined to small volumes only. It is clear that the upscaling of the UST technology can be achieved only if the treatment takes place above the primary solidification range of aluminum, when the alloy is still in fully liquid state. ${ }^{17}$ Therefore, our strategy for upscaling is to move the location of the UST, which was conventionally done in the hot top or distribution bag of a DC casting mold (see the review in Ref. $10)$, into the DC casting launder.

In this work, we performed casting experiments in a pilot-scale DC casting facility in the Advanced Metal Casting Center (AMCC) of the Brunel Center of Advanced Solidification Technology (BCAST) at Brunel University London. We performed DC casting of an AA6XXX-series aluminum alloy with and without UST treatment in the DC casting launder. $\mathrm{Zr}$ was deliberately added to the alloy to provide primary $\mathrm{Al}_{3} \mathrm{Zr}$ particles that should act as solidification substrates for $\mathrm{Al}$, and this action should be improved by UST, which is expected to refine and multiply these primary intermetallics. Two casting temperatures were used to observe their effect on the resulting microstructure of the cast billets. Microstructure analysis, including quantitative analysis of grain size and $\mathrm{Al}_{3} \mathrm{Zr}$ particles (i.e., size and number density), was carried out to assess the effect of casting temperature and UST.

Suggestions and numerical simulation results on the optimization of UST in a DC casting launder are also provided. The outcome of this research serves as a proof of concept on the feasibility of structure refinement of DC casting billet by employing UST in the DC casting launder and also provides groundwork for upscaling UST towards industrial-level melt processing.

\section{MATERIALS AND METHODS}

A customized AA6XXX-series aluminum alloy was used as a base alloy with 0.2 wt. $\% \mathrm{Zr}$ added. No AlTiB grain refiner was added. The chemical composition of the melt prior to casting was analyzed by optical emission spectroscopy (OES) and is presented in Table I. All the chemical compositions described in this work are in weight percent (wt.\%).

A pilot-scale DC caster with a hot top setup, which is able to produce 152-mm-diameter billets, was utilized for our experiment. More information regarding the DC casting setup can be found elsewhere. ${ }^{23}$ Two billets were cast with a casting speed of $140 \mathrm{~mm} / \mathrm{min}$. One billet was cast at $650^{\circ} \mathrm{C}$ (lower casting temperature), whereas the other one was cast at $665^{\circ} \mathrm{C}$ (higher casting temperature). Thermodynamic calculations (ThermoCalc software with TCAL4 database) for the alloy with the composition presented in Table I give a liquidus temperature of $\mathrm{Al}_{3} \mathrm{Zr}$ of $733^{\circ} \mathrm{C}$ and formation of $\alpha$ aluminum starting at $651^{\circ} \mathrm{C}$. Note that the temperature was controlled by a K-thermocouple placed in the hot top while the UST was performed in the launder, where the melt was a few degrees higher in temperature. A DC casting launder was used to transfer the melt from the furnace to the DC casting hot top. The cross section of the launder has an inverted trapezoid shape, with width and height of approximately $75 \mathrm{~mm}$ and $78 \mathrm{~mm}$, respectively.

UST was performed in the DC casting launder using a water-cooled 5-kW magnetostrictive transducer (Reltec) operating at $17.3 \mathrm{kHz}$ with the power set to $3.5 \mathrm{~kW}$ (approximately $40 \mu \mathrm{m}$ peak-to-peak amplitude) during the treatment, because according to previous work ${ }^{24}$ this setting produced the highest cavitation intensity in liquid Al. The treatment was performed continuously in the DC casting launder with a $\mathrm{Nb}$ conical sonotrode $(20 \mathrm{~mm}$ diameter $)$

Table I. Chemical composition of alloy obtained by optical emission spectroscopy (OES)

\begin{tabular}{llllllll}
\hline $\mathbf{A l}$ & $\frac{\mathbf{S i}}{0.8}$ & $\frac{\mathbf{C u}}{0.73}$ & $\frac{\mathbf{M g}}{0.68}$ & $\frac{\mathbf{M n}}{0.48}$ & $\frac{\mathbf{Z r}}{0.21}$ & $\frac{\mathbf{F e}}{0.2}$ & $\frac{\mathbf{T i}}{0.04}$ \\
\hline Balance & 0.8 &
\end{tabular}


immersed approximately $12 \mathrm{~mm}$ below the melt surface and approximately $250 \mathrm{~mm}$ upstream from the DC casting hot top. The sonotrode remained submerged in the melt flow throughout the entire casting process. Each billet was cast to a length of approximately $1 \mathrm{~m}$. To compare the effect between UST and non-UST conditions, the ultrasonic transducer was only activated after the steady-state regime had been reached and the first half of the billet had been cast (approximately $0.5 \mathrm{~m}$ of the billet length).

For microstructure analysis, samples were cut from each billet in the horizontal direction. One set was cut from the part of the billet without UST treatment (after steady-state casting was reached), whereas the other set was cut from the part of the billet with UST treatment. For each set of samples, we performed observations at three radial positions: billet center, mid-radius, and surface. For metallographic observation, samples were mechanically ground, polished, then examined under a light optical microscope (Zeiss Axio Scope.A1). For grain size analysis, the polished samples were subsequently anodized using Barker's solution $\left(5 \% \mathrm{HBF}_{4}\right.$ in water solution) for approximately $1 \mathrm{~min}$ at 20 $V_{\text {DC. }}$ Grain size analysis was performed using the linear intercept method with at least 400 intercepts made on each sample to obtain statistical soundness. Particle number density was calculated by counting the number of lines (which were randomly placed in optical micrograph fields of view) that intercept with $\mathrm{Al}_{3} \mathrm{Zr}$ intermetallics, divided by the total number of lines used in the analysis of each condition (a total of 100 intercept lines were used to analyze each processing condition-a combination of UST application and cast temperature). $\mathrm{Al}_{3} \mathrm{Zr}$ intermetallics were examined using a scanning electron microscope (SEM, JCM-6000; JEOL) equipped with energy dispersive $\mathrm{x}$-ray sensor (EDS).

Numerical simulations of UST treatment in a DC casting launder with settings (e.g., launder geometry, sonotrode tip geometry and immersion level, etc.) imitating the experimental conditions were carried out in two dimensions (2D) to provide guidelines on the optimization of UST in the melt flow by using flow control partitions. A state-of-theart numerical model coupling the acoustic cavitation, acoustic flow, and macroscopic fluid flow is used. A nonlinear Helmholtz-type model ${ }^{25}$ has been especially developed in COMSOL to model the acoustic pressure field accounting for the effect of cavitation. This is given in Eq. 1 , where $P$ represents the complex acoustic pressure field, and $k_{\mathrm{m}}^{2}$ is a modified wave number given by Eq. 2:

$$
\begin{gathered}
\nabla^{2} P+k_{\mathrm{m}}^{2} P=0 \\
k_{\mathrm{m}}^{2}=\left(\frac{\omega}{c}\right)^{2}-W(|P|)\left(\frac{\mathcal{A}(P)}{|P|}+i \frac{\mathcal{B}(P)}{|P|}\right),
\end{gathered}
$$

where $\omega$ is the angular frequency and $c=4600 \mathrm{~m} /$ $\mathrm{s}$ is the speed of sound in liquid Al. The dissipation functions $\mathcal{A}$ and $\mathcal{B}$ take the same form as in Ref. 25 , with the inclusion of a smoothed ramp function $W$ centered on the Blake threshold to aid convergence. $k_{\mathrm{m}}^{2}$ describes the change in speed of sound and attenuation due to the presence of inertially cavitating bubbles. To model these bubbles, the KellerMiksis (KM) approach ${ }^{26}$ is used, as given in Eq. 3.

$$
\begin{aligned}
& \left(1-\frac{\dot{R}}{C}\right) R \ddot{R}+\frac{3}{2} \dot{R}^{2}\left(1-\frac{\dot{R}}{3 c}\right) \\
& =\frac{1}{\rho_{1}}\left(1+\frac{\dot{R}}{c}+\frac{R}{c} \frac{\mathrm{d}}{\mathrm{d} t}\right)\left[p_{1}-p(t)\right]
\end{aligned}
$$

Here $p_{1}$ represents the liquid pressure at the liquidgas interface. The pressure $p(t)=p_{0}(1-A \sin (\omega t))$ accounts for the atmospheric and acoustic pressures. The amplitude parameter $A$ is chosen to be 2.4 here, matching that of the expected readings from experiments in liquid aluminum. ${ }^{27}$

Once the acoustic pressure field is calculated, it is coupled to the turbulent flow module incorporating the $k-\varepsilon$ Reynolds-averaged Navier-Stokes (RANS) turbulence model $^{28}$ in COMSOL Multiphysics by the inclusion of a streaming volume force $f=\nabla(\rho v \bar{\otimes} v)$, where $v$ is the acoustic velocity, and the simulation runs until the flow reaches steady state. Boundary conditions of the numerical simulations are summarized in Table II. The fluid velocity field can then be used to estimate the residence time of tracers released into the liquid aluminum, which is defined as the time spent in a region with an acoustic pressure higher than the Blake threshold. A massless Lagrangian particle model is used, as given in Eq. 4, where $q$ is the position of a tracer.

$$
\frac{\mathrm{d} q}{\mathrm{~d} t}=v
$$

For each launder geometry, 10,000 tracer particles are released at $t=0 \mathrm{~s}$ and placed uniformly in the region upstream to the processing zone between the partitions. Each simulation is run for $260 \mathrm{~s}$, allowing for the majority of the tracer particles to recirculate and collect at an outlet placed downstream.

\section{RESULTS}

Figure 1 shows that UST treatment in the DC casting launder was able to refine the grain structure of the alloy and demonstrates the robustness of the grain structure achieved by UST with respect to the casting temperature difference. For the billet cast without UST at $665^{\circ} \mathrm{C}$, the grains are rather coarse and developed a dendritic morphology (Fig. 1a). At the lower casting temperature, the microstructure reveals two grain morphologies (Fig. 1), i.e., some of the grains are large and have a floating grain morphology-large dendrite arms 


\section{Table II. Boundary conditions of numerical simulations}

\section{Helmholtz-type acoustic pressure model}

Free surface: $P=0$

Partitions, sonotrode walls, launder walls: Zero flux (i.e., $\nabla P=0$ )

Sonotrode: $\nabla P=\frac{1}{2} \rho u \omega^{2}$ ( $u$ is peak-to-peak displacement and $P$ is the acoustic pressure)

\section{Turbulent flow $(k-\varepsilon$ RANS) model}

All walls: no-slip boundary condition Mass flow inlet: $5.94 \mathrm{~kg} / \mathrm{min}$ (approx. $2.5 \mathrm{~L} / \mathrm{min}$ volumetric)

Outlet pressure: $p_{\mathrm{f}}=0$

( $p_{\mathrm{f}}$ is the fluid pressure)
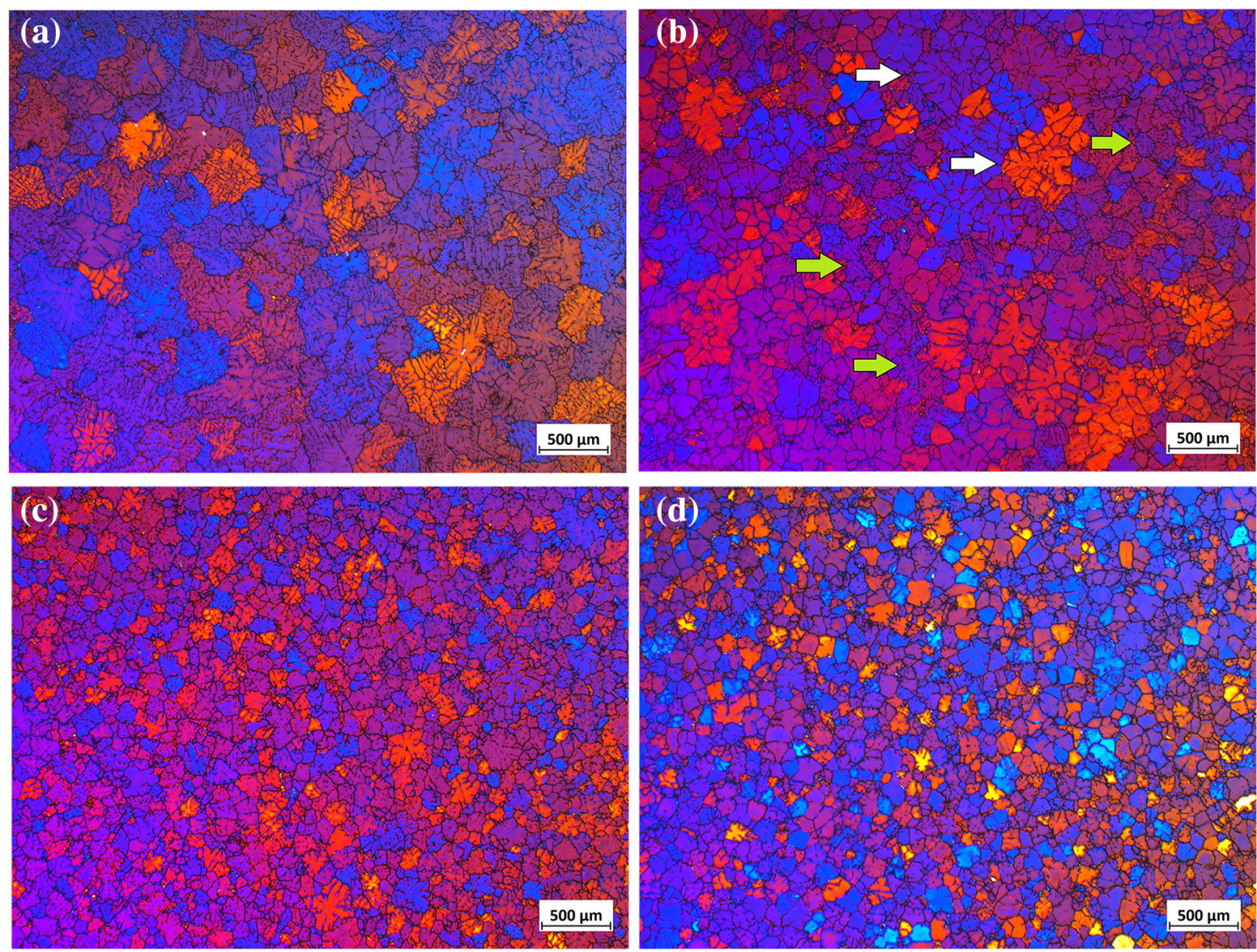

Fig. 1. Typical grain morphologies at different UST conditions and casting temperatures at the billet center: without UST at (a) higher and (b) lower casting temperature, and with UST at (c) higher and (d) lower casting temperature.

spacing and thicker dendrite arms (indicated by white arrows in Fig. 1b), while others are smaller and have dendritic morphology (indicated by green arrows in Fig. 1b). The application of UST in the DC casting launder refines the grain structure irrespective of the casting temperature, producing either fine dendritic grains or grains that seem to be fragmented having a globular morphology (Fig. 1c and $\mathrm{d}$ ).

Figure 2 provides quantitative information on the grain size and shows that the alloy cast (without UST) at $665^{\circ} \mathrm{C}$ produces larger grains as compared with the one cast at $650^{\circ} \mathrm{C}$. The application of UST reduced the average grain size by $52 \%$ (billet center) and $67 \%$ (billet surface) for the billet cast at $665^{\circ} \mathrm{C}$, and by about $39 \%$ (billet center) and $43 \%$ (billet surface) for the billet cast at $650^{\circ} \mathrm{C}$, bringing both grain structures down to the same size. Hence, the casting temperature apparently has no impact on the average grain size of post-UST-treated billets. The application of UST also seems to homogenize the grain structure, as indicated by the reduction of the error bars on the grain size measurements presented in Fig. 2.

In the non-UST billets, the $\mathrm{Al}_{3} \mathrm{Zr}$ particles were mostly found in the center of the grains regardless of the casting temperature, as shown for example in Fig. 3a. When UST was applied, the number of 

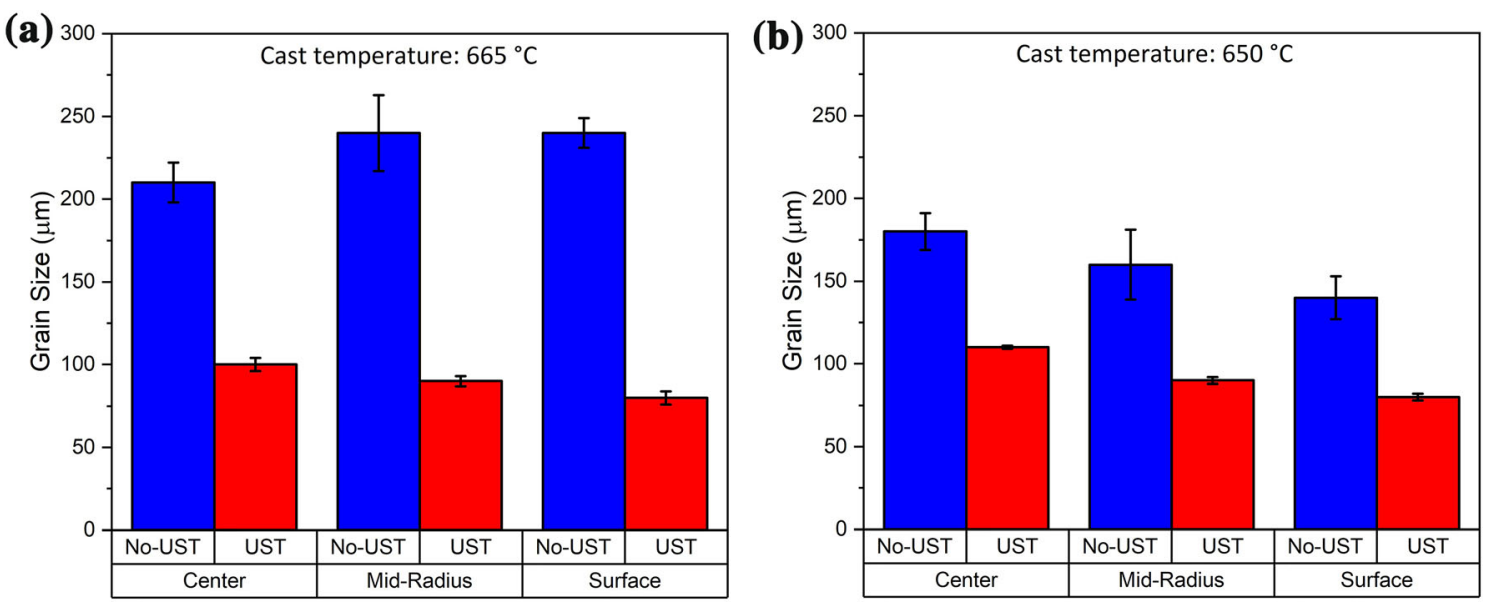

Fig. 2. Effect of UST and position in the billet on the average grain size at (a) higher $\left(665^{\circ} \mathrm{C}\right)$ and (b) lower $\left(650^{\circ} \mathrm{C}\right)$ casting temperature.
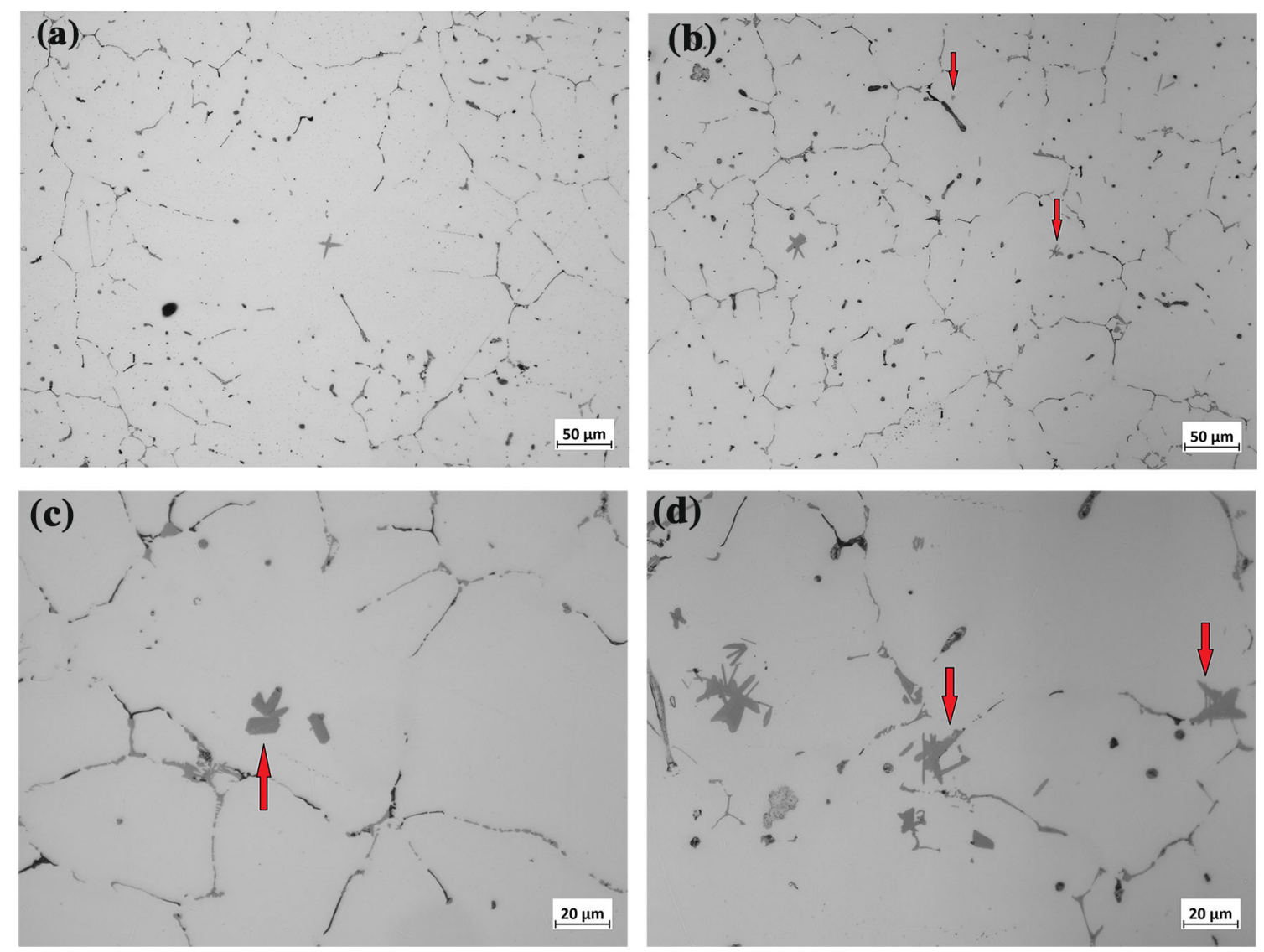

Fig. 3. Optical microscope observations of $\mathrm{Al}_{3} \mathrm{Zr}$ particles in billets cast at $665^{\circ} \mathrm{C}$ (a) without UST and (b) with UST. Growth morphologies of $\mathrm{Al}_{3} \mathrm{Zr}$ particles with UST applied at cast temperature of (c) $650^{\circ} \mathrm{C}$ and (d) $665^{\circ} \mathrm{C}$.

$\mathrm{Al}_{3} \mathrm{Zr}$ particles increased in the sample, and these particles were not only located at grain centers but also in other parts of the grains (e.g. closer to the grain boundaries, Fig. 3b, c and d; examples are indicated by red arrows). Something worth noting is that, in the microstructure of the billet cast at $665^{\circ} \mathrm{C}$
(Fig. 3d), the $\mathrm{Al}_{3} \mathrm{Zr}$ particles were found to be more clustered and agglomerated than in the billet cast at $650^{\circ} \mathrm{C}$ (Fig. 3c).

SEM backscatter-mode analysis (Fig. 4a) and EDS mapping (Fig. 4b) confirmed that the intermetallic particles found in the middle of the grains 

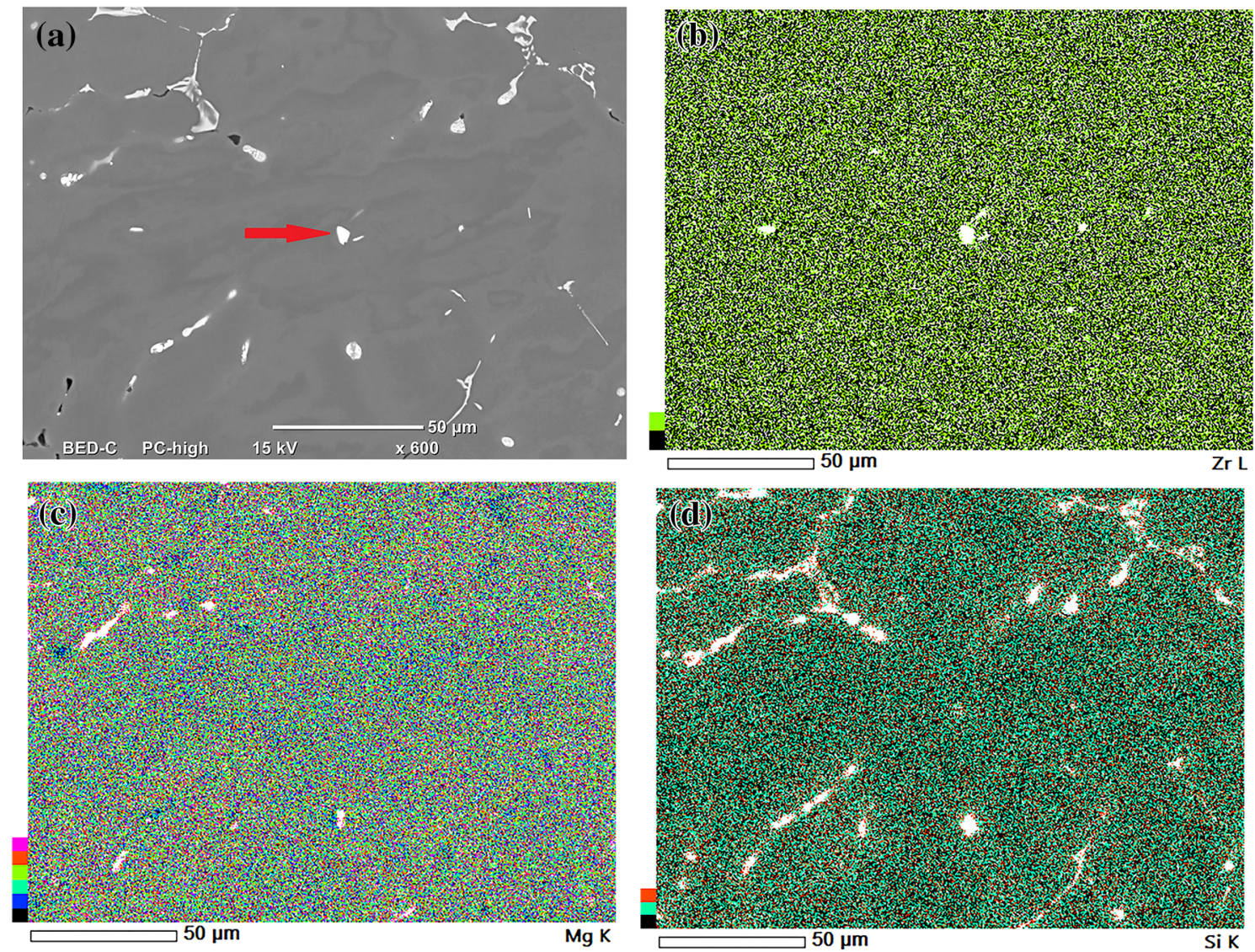

Fig. 4. Observation of microstructure: (a) SEM in backscatter mode, $\mathrm{Al}_{3} \mathrm{Zr}$ is indicated by an arrow; (b-d) EDS mapping of main elements: (b) $\mathrm{Zr}$, (c) $\mathrm{Mg}$, and (d) Si.

(indicated by red arrow in Fig. 4a) were $\mathrm{Al}_{3} \mathrm{Zr}$. Meanwhile, the intermetallics located in the grain boundary regions are most probably Mg-based intermetallics such as $\mathrm{Mg}_{2} \mathrm{Si}$ (Fig. 4c) and Si-containing intermetallics such as $\mathrm{Al}_{5} \mathrm{Cu}_{2} \mathrm{Mg}_{8} \mathrm{Si}_{6}$ and $\mathrm{AlFeSi}$ phases ${ }^{29}$ (Fig. 4d), of eutectic origin.

The number of $\mathrm{Al}_{3} \mathrm{Zr}$ particles increased with the application of UST in the launder, and the distribution of the particle size shifted towards lower values as shown in Fig. 5. Larger $\mathrm{Al}_{3} \mathrm{Zr}$ intermetallics seemed to be found in the billet cast at $665^{\circ} \mathrm{C}$ (high casting temperature) (Fig. 5a). Even though this trend was similar between the high and low casting temperatures, the fragmentation effect seemed to be more pronounced in the alloy cast at $665^{\circ} \mathrm{C}$, in terms of both the shift of the average particle size to lower values (Fig. 5a and c) and the increase of the particle number (Fig. 5e). It is worth mentioning that particle refinement upon UST resulted in the formation of particles smaller than $5 \mu \mathrm{m}$ (indicated by the 0-5 bin) (Fig. $5 \mathrm{c}$ and d), which are most important for grain refinement. ${ }^{17}$ Note that the average $\mathrm{Al}_{3} \mathrm{Zr}$ particle size was similar for both casting temperature, being around $11.5 \mu \mathrm{m}$. Meanwhile, the increase in the amount of particles in the alloy is quantified through the particle number density analysis (Fig. 5e). UST almost doubled the number of particles.

As a way to improve the efficiency of UST (obviously related to the residence time of the melt under active cavitation conditions), we performed computer simulation of melt flow and acoustic conditions in the case of managed flow in a launder with partitions. Figure $6 \mathrm{a}$ and $\mathrm{b}$ shows that the area with higher acoustic pressure (i.e., above $217 \mathrm{kPa}$, which is the Blake threshold in liquid $\mathrm{Al}$ ) in the simulation of UST in a DC casting launder without partitions (Fig. 6a) is smaller in comparison with the one with partitions (Fig. 6b). This is especially noticeable in the vicinity of the partitions, where an approximately twofold increase in acoustic pressure magnitude is predicted. Two vortices (clockwise towards upstream and counterclockwise towards downstream) were observed in the tracer particle plot (Fig. 6c). The particles, especially those heading downstream, in the vortex with counterclockwise direction generally have higher velocity than the particles in the clockwise vortex. According to the histogram in Fig. 6d, nearly all the tracer particles pass through the area where intense 

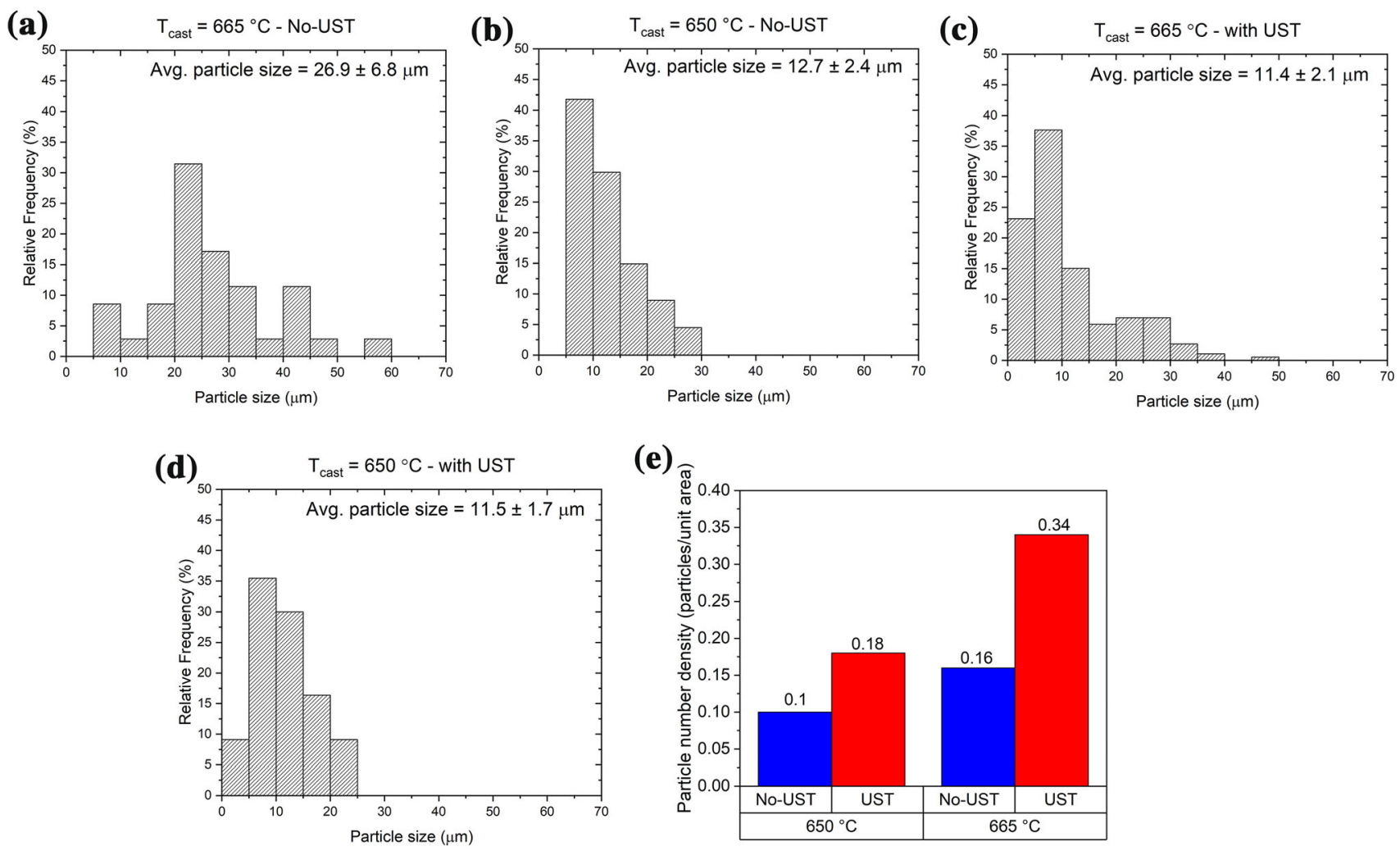

Fig. 5. Distribution of $\mathrm{Al}_{3} \mathrm{Zr}$ particle size at billet center without UST at (a) higher $\left(665^{\circ} \mathrm{C}\right)$ and (b) lower $\left(650^{\circ} \mathrm{C}\right)$ casting temperature, and with UST at (c) higher $\left(665^{\circ} \mathrm{C}\right)$ and $(\mathrm{d})$ lower $\left(650^{\circ} \mathrm{C}\right)$ casting temperature. (e) $\mathrm{Al}_{3} \mathrm{Zr}$ particle number density analysis at different UST conditions and casting temperatures.

cavitation occurs (the highlighted zone under the sonotrode in Fig. 6c) at least once, and are processed for $0.1 \mathrm{~s}$ or more. Progressively a smaller number of particles recirculate multiple times, with the longest recorded time being $3.16 \mathrm{~s}$. The distribution of residence times shown in Fig. $6 \mathrm{c}$ informs us that the particles are generally processed longer in the case of partitions (recorded mean of $0.597 \mathrm{~s}$ ) than without partitions (recorded mean of $0.496 \mathrm{~s}$ ). In addition, it seems that there is a minor distribution hump between $t=1.2 \mathrm{~s}$ and $1.6 \mathrm{~s}$ for the case without partitions, while the simulation with partitions shows a similar hump but occurring approximately between $t=2.3 \mathrm{~s}$ and $2.7 \mathrm{~s}$.

\section{DISCUSSION}

The microstructure of the billets cast without UST shows that the grain size was larger when the casting temperature was higher (Fig. 1a and b). This is in general a common phenomenon in casting, being related to the amount of active solidification sites available for nucleation. ${ }^{2,30}$ It is worth noting that, in the billets that were cast with UST, the difference in casting temperature did not significantly influence the resulting grain size (Figs. 1c, d, and 2). This may suggest that the number of solidification substrates was sufficient and not influenced by the melt temperature, as UST plays a dominant role in activating and multiplying potential nuclei. ${ }^{10}$ In the case of this study, the active nuclei for the $\mathrm{Al}$ solid solution are primary $\mathrm{Al}_{3} \mathrm{Zr}$ particles.

In the current work, we demonstrated that the combined effect of UST and $\mathrm{Zr}^{17,31}$ could be achieved upon pilot-scale DC casting $(\varnothing=152 \mathrm{~mm})$ while applying UST in the launder. The achieved refinement of grain size by more than $50 \%$ in the billet center demonstrates the effectiveness of $\mathrm{Zr}\left(\mathrm{Al}_{3} \mathrm{Zr}\right)$ as a grain refiner agent when UST was applied to the melt flow (rather than to a fixed volume in the billet sump or in a crucible), potentially lifting the restrictions on further upscaling. From the chemical composition analysis (Table I), we can see that the amount of $\mathrm{Zr}$ in the alloy was $0.21 \%$, which is beyond its solubility limit in $\mathrm{Al}(0.11 \%)$. This supports findings from earlier studies ${ }^{8,9,17}$ that addition of $\mathrm{Zr}$ at $0.18 \%$ to $0.2 \%$ produces significant grain refinement in $\mathrm{Al}$, especially when UST is applied in the temperature range of the $\mathrm{Al}_{3} \mathrm{Zr}$ primary solidification. The grain refinement may be additionally assisted by the presence of $\mathrm{Ti}$ in the alloy (with a content of $0.04 \%$ in our case; Table I) with $\mathrm{Ti}$ acting as a growth restriction element. ${ }^{32}$ Note that, without UST, the action of this mechanism is weak, as illustrated by comparison of Fig. $1 \mathrm{a}, \mathrm{b}, \mathrm{c}$ and $\mathrm{d}$. It is quite obvious that the 

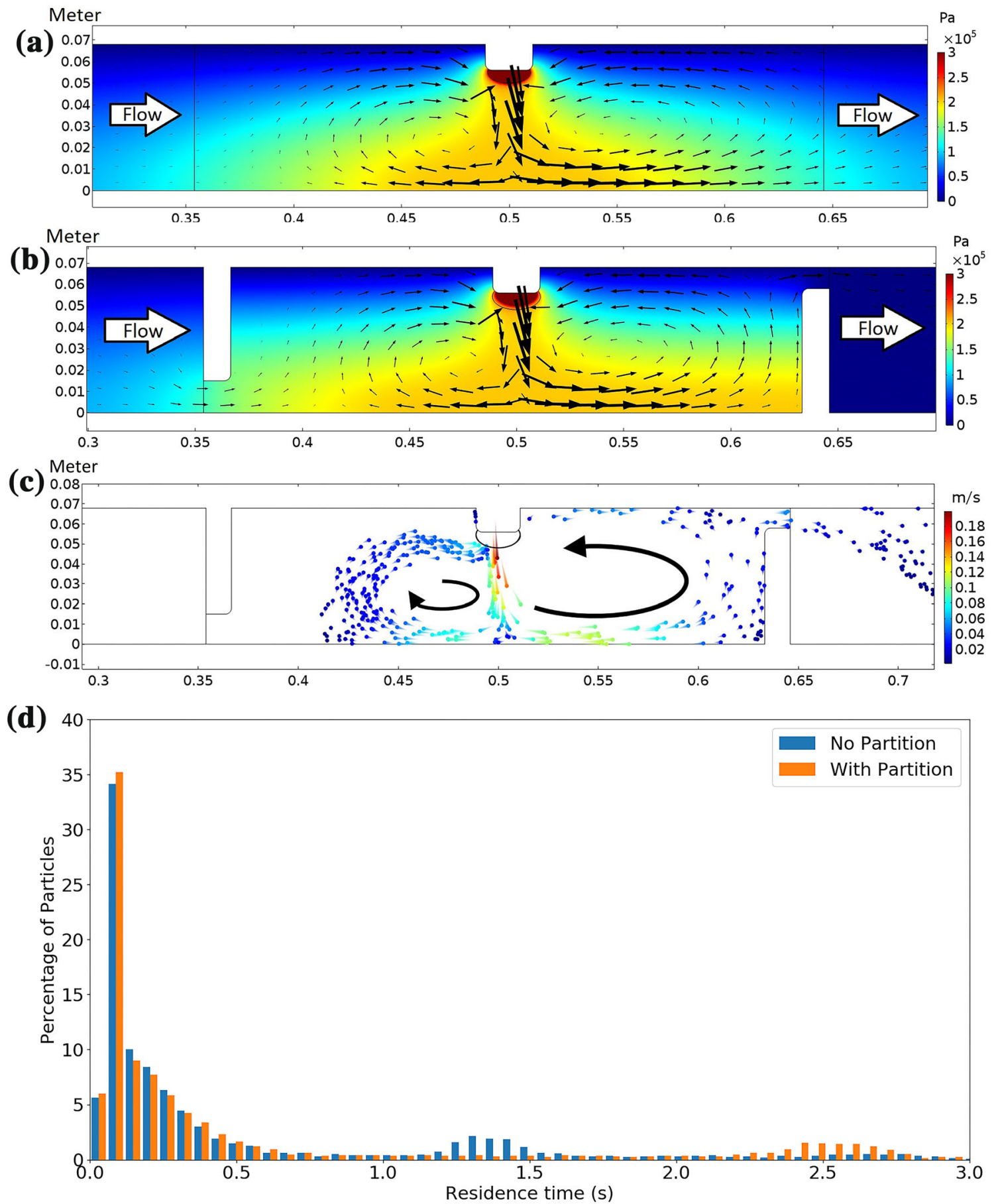

Fig. 6. Numerical simulation results of UST in a DC casting launder. Acoustic pressure distribution in the case (a) without and (b) with partitions. Flow from left to right, with streamlines shown. (c) Particle trajectories at $t=125 \mathrm{~s}$, with recirculation shown. Elliptical area under the sonotrode marks the processing region with an acoustic pressure greater than the Blake threshold. (d) Particle processing time histogram which reflects the residence time of particles, with and without partitions.

number density (Fig. 5e) and the size of the primary intermetallics (Fig. 5a, b, c and d) are important for triggering this mechanism, as suggested before. ${ }^{17}$

The particle number density and size analysis (Fig. 5) show that the application of UST in the DC casting launder decreases the average $\mathrm{Al}_{3} \mathrm{Zr}$ particle size but simultaneously increases their number, which demonstrates the successful translation of the UST effect from the laboratory scale to pilot scale. The observed phenomena are likely to be a result of $\mathrm{Al}_{3} \mathrm{Zr}$ fragmentation caused by collapsing acoustic bubbles. The necessary condition for this to occur is that UST be performed across or below the liquidus of the $\mathrm{Al}_{3} \mathrm{Zr}$ phase. The presence of $\mathrm{Al}_{3} \mathrm{Zr}$ in the alloys even without UST testifies that the melt temperature was low enough to allow for the 
formation of the primary particles in the launder. This "premature" formation of the particles in the launder may explain the rather counterintuitive observation that the alloy cast at $650^{\circ} \mathrm{C}$ (without UST) had a lower particle number density and a smaller average $\mathrm{Al}_{3} \mathrm{Zr}$ particle size than the one cast at $665^{\circ} \mathrm{C}$. Logically, larger $\mathrm{Al}_{3} \mathrm{Zr}$ particles should be found in the alloy cast at a lower temperature as they would have more time to grow. However, in reality, the larger particles that formed at a lower temperature in the melt flow in the launder may sediment to the bottom of the launder before reaching the hot top, thus being taken out of commission.

The small particles, finer than $5 \mu \mathrm{m}$, would be the most potent for nucleating $\mathrm{Al}$ grains. ${ }^{9,17}$ This fraction of primary particles is formed only upon UST, as shown in Fig. $5 \mathrm{c}$ and $\mathrm{d}$. In addition to those, clusters of $\mathrm{Al}_{3} \mathrm{Zr}$ particles were observed in the structure of the billet cast with UST, at both casting temperatures (Fig. 3c and d). Such branching structure resembles flat $\mathrm{Al}_{3} \mathrm{Zr}$ dendrites observed in previous work. ${ }^{33}$ However, the peculiar $\mathrm{Al}_{3} \mathrm{Zr}$ formations (i.e., formation of $\mathrm{Al}_{3} \mathrm{Zr}$ clusters that resemble fragmented particles reconnected together and formed branching structures which deviate from the particle's original morphology shown in Refs. ${ }^{33},{ }^{34}$ indicated by red arrows in Fig. 3c and $d$ may suggest that some of the $\mathrm{Al}_{3} \mathrm{Zr}$ plates fragmented by cavitation may be fused with other fragments at the matching facet surface upon their travel in the melt due to the low melt temperature. The clustering or agglomeration of $\mathrm{Al}_{3} \mathrm{Zr}$ resembles the microstructure observed by Zhang et al. ${ }^{31}$ In their work, such $\mathrm{Al}_{3} \mathrm{Zr}$ agglomeration was typically found when a lower UST power was employed. This agglomeration was not observed anymore when the UST power was increased. Therefore, the $\mathrm{Al}_{3} \mathrm{Zr}$ agglomeration shown in Fig. 3c and d may represent a structure with suboptimal UST treatment. In our case, the melt temperature may be too low.

The structure refinement demonstrated in this work reveals a promising path for upscaling of UST towards industrial-scale applications. In addition, when UST is performed while the metal is still in its fully liquid state (i.e., in the melt flow), additional benefits from UST such as melt degassing ${ }^{10}$ can also be attained. In contrast, the degassing effect would be minimal or even detrimental if the UST were performed in the hot top, as there would be no time for gas release.

This work also demonstrates the pathway to further optimization of this treatment configuration. Two points that require attention are the treatment temperature and processing time.

From the treatment temperature point of view, previous studies have suggested that the optimum temperature range of UST would be across the liquidus line of $\mathrm{Al}_{3} \mathrm{Zr}{ }^{9,33}$ This means temperatures between $690^{\circ} \mathrm{C}$ and $733^{\circ} \mathrm{C}$ for $0.2 \% \mathrm{Zr}$. Another point to take into account is that the viscosity of molten $\mathrm{Al}$ increases as the temperature decreases. ${ }^{35}$ Based on a study on liquids with different viscosity, it seems that the UST effect should be more effective (i.e., larger cavitation zone) in a less viscous liquid. ${ }^{27}$ Since in this work we performed UST at rather low temperatures (i.e., during the growth phase of $\mathrm{Al}_{3} \mathrm{Zr}$ ), further efficiency increases should be expected when the UST is performed at higher melt temperatures (as mentioned above), which will also be beneficial for degassing and melt flow management. ${ }^{10}$

Concerning the treatment time, longer processing time typically leads to better treatment efficiency, i.e., for structure refinement, ${ }^{17}$ degassing, ${ }^{36}$ and particle deagglomeration effect. ${ }^{37}$ One possible strategy to increase the actual cavitation processing time is to deploy an innovative melt-flow management system as proposed by Tzanakis et al. ${ }^{38}$ and Lebon et al. ${ }^{39}$ There are two main objectives of this approach: first, to exploit the acoustic resonance condition-the increase of acoustic bubble fraction, and hence the treatment quality, when the distance between partitions is equal to or an integer multiple of the ultrasonic wavelengths in the melt, ${ }^{39}$ and second, to increase the residence time within the active cavitation zone (the residence time of the melt in the active treatment zone in the DC casting launder) by flow management. The authors have performed preliminary studies based on this optimization strategy, albeit mostly on water and liquid $\mathrm{Al}$ in a model launder, ${ }^{40,41}$ with encouraging results. In this study we applied the same approach to simulating the UST in the melt flow with partitions. The simulation results presented in Fig. 6 demonstrate that the usage of the flow management system (i.e., partitions) is beneficial as it provides a larger cavitation-intense area and longer treatment of the particles (longer residence time). The latter is supported not only by the fact that the particles have a longer mean value in terms of processed time but also because the secondary hump of the case with partitions (Fig. 6d) is shifted towards longer residence time, which signifies that more particles are processed for longer as compared with the case without partitions. The presence of partitions increases the area with higher acoustic pressure (i.e., above the Blake threshold of $217 \mathrm{kPa}$ ), thus providing a larger cavitation-active area. In addition, the acoustic pressure value obtained from the numerical simulation is a timeaveraged acoustic pressure, which in the experiment is closely represented by the square root of the mean pressure value (RMS value) while the maximum pressure might be several times higher. ${ }^{41}$ In addition, the cavitation bubbles generated in the cavitation zone are transported to the areas where the pressure is still sufficient for their pulsation and implosion, increasing the active processing area. Those conditions suggest a better UST treatment efficiency. Therefore, the optimization of the flow management system in the launder upon UST based on this model and its validation in pilot-scale DC casting are the next steps to be undertaken. 


\section{CONCLUSION}

We carried out UST in the melt flow in a launder of a pilot-scale DC casting process. The effect of UST was observed, and two casting temperatures $\left(650^{\circ} \mathrm{C}\right.$ and $665^{\circ} \mathrm{C}$ ) were applied to assess their effect on the resulting microstructure (i.e., grain size and $\mathrm{Al}_{3} \mathrm{Zr}$ particle statistics). The results obtained from this work can be summarized as follows:

1. It is demonstrated that the application of UST in a DC casting launder is a promising way of upscaling UST technology towards industrialscale applications.

2. Application of UST in the melt flow in a launder reduces the grain size by around 50\% (in the billet center) as compared with conventional DC casting, irrespective of the melt temperature. The reduction in grain size is greater towards the surface of the billet.

3. UST refines the $\mathrm{Al}_{3} \mathrm{Zr}$ intermetallics and increases their number density in the alloy. The refined and multiplied primary $\mathrm{Al}_{3} \mathrm{Zr}$ particles are the main source of grain refining upon UST.

4. Results from numerical simulations show that the utilization of a flow management system (i.e., partitions) provides larger cavitation-intense area and longer residence time, which may improve the outcome of UST in a DC casting launder.

5. The next steps for further increasing the efficiency of UST in the melt flow may be as follows: (a) UST should be carried out at a higher melt temperature (across the liquidus of $\mathrm{Al}_{3} \mathrm{Zr}$ for a particular alloy composition) yet low enough to enable efficient cavitation and degassing, and (b) the residence time of the melt subjected to UST should be increased through melt-flow management optimized using numerical modeling.

\section{ACKNOWLEDGEMENTS}

Financial support from EPSRC (UK) under Projects UltraMelt2 (EP/R011001/1, EP/R011044/1, and EP/R011095/1) is gratefully acknowledged. The authors are grateful for the support of Constellium and personally Prof. M. Jarrett in organizing DC casting experiments at AMCC/BCAST.

\section{OPEN ACCESS}

This article is licensed under a Creative Commons Attribution 4.0 International License, which permits use, sharing, adaptation, distribution and reproduction in any medium or format, as long as you give appropriate credit to the original author(s) and the source, provide a link to the Creative Commons licence, and indicate if changes were made. The images or other third party material in this article are included in the article's Creative
Commons licence, unless indicated otherwise in a credit line to the material. If material is not included in the article's Creative Commons licence and your intended use is not permitted by statutory regulation or exceeds the permitted use, you will need to obtain permission directly from the copyright holder. To view a copy of this licence, visit $h$ ttp://creativecommons.org/licenses/by/4.0/.

\section{REFERENCES}

1. D.A. Granger, Treatise on Materials Science and Technology (Amsterdam: Elsevier, 1989), p. 109.

2. J.F. Grandfield, D.G. Eskin, and I.F. Bainbridge, eds., Direct-Chill Casting of Light Alloys: Science and Technology (Hoboken: Wiley, 2013).

3. D.G. Eskin, S. Suyitno, and L. Katgerman, Prog. Mater Sci. 49, 629 (2004).

4. S. Li, K. Sadayappan, and D. Apelian, Metall. Mater. Trans. B 44, 614 (2013).

5. F. Stachowicz, J. Mech. Work. Technol. 13, 229 (1986).

6. T.G. Langdon, Acta Mater. 61, 7035 (2013).

7. B.S. Murty, S.A. Kori, and M. Chakraborty, Int. Mater. Rev. 47, 3 (2002).

8. F. Wang, D. Qiu, Z.-L. Liu, J.A. Taylor, M.A. Easton, and M.-X. Zhang, Acta Mater. 61, 5636 (2013).

9. T.V. Atamanenko, D.G. Eskin, M. Sluiter, and L. Katgerman, J. Alloys Compd. 509, 57 (2011).

10. G.I. Eskin and D.G. Eskin, Ultrasonic Treatment of Light Alloy Melts, 2nd ed. (Boca Raton: CRC Press, 2015).

11. I. Tzanakis, D.G. Eskin, A. Georgoulas, and D.K. Fytanidis, Ultrason. Sonochem. 21, 866 (2014).

12. F. Wang, I. Tzanakis, D. Eskin, J. Mi, and T. Connolley, Ultrason. Sonochem. 39, 66 (2017).

13. M. Zhang, P. Kelly, M. Easton, and J. Taylor, Acta Mater. 53, 1427 (2005).

14. F. Wang, D. Qiu, Z. Liu, J. Taylor, M. Easton, and M. Zhang, Trans. Nonferrous Met. Soc. China 24, 2034 (2014).

15. G. Zhong, S. Wu, H. Jiang, and P. An, J. Alloys Compd. 492, $482(2010)$

16. Y. Zhang, J. Jie, Y. Gao, Y. Lu, and T. Li, Intermetallics 42, 120 (2013).

17. T.V. Atamanenko, D.G. Eskin, L. Zhang, and L. Katgerman, Metall. Mater. Trans. A 41, 2056 (2010).

18. D. Qiu, J.A. Taylor, and M.-X. Zhang, Metall. Mater. Trans. A 41,3412 (2010).

19. M.A. Easton and D.H. StJohn, Acta Mater. 49, 1867 (2001).

20. V.M. Sreekumar and D.G. Eskin, JOM 68, 3088 (2016).

21. L. Zhang, R. Li, R. Jiang, L. Zhang, and X. Li, JOM 71, 2063 (2019).

22. Z. Liu, R. Li, R. Jiang, L. Zhang, and X. Li, Metall. Mater. Trans. A 50, 1146 (2019).

23. G. Salloum-Abou-Jaoude, D.G. Eskin, G.S.B. Lebon, C. Barbatti, P. Jarry, and M. Jarrett, Light Metals 2019, ed. C. Chesonis (Cham: Springer, 2019), p. 1605.

24. I. Tzanakis, G.S.B. Lebon, D.G. Eskin, and K. Pericleous, Mater. Des. 90, 979 (2016).

25. F.J. Trujillo, Ultrason. Sonochem. 47, 75 (2018).

26. J.B. Keller and M. Miksis, J. Acoust. Soc. Am. 68, 628 (1980).

27. G.S.B. Lebon, I. Tzanakis, K. Pericleous, and D. Eskin, Ultrason. Sonochem. 42, 411 (2018).

28. B.E. Launder and D.B. Spalding, Comput. Methods Appl. Mech. Eng. 3, 269 (1974).

29. X. Dong, S. Amirkhanlou, and S. Ji, Sci. Rep. 9, 9582 (2019).

30. D.G. Eskin, V.I. Savran, and L. Katgerman, Metall. Mater. Trans. A 36, 1965 (2005).

31. L. Zhang, D.G. Eskin, A.G. Miroux, and L. Katgerman, IOP Conf. Ser. Mater. Sci. Eng. 27, 012002 (2012).

32. M. Easton and D. StJohn, Metall. Mater. Trans. A 30, 1625 (1999). 
33. F. Wang, D. Eskin, T. Connolley, and J. Mi, Trans. Nonferrous Met. Soc. China 27, 977 (2017).

34. A. Priyadarshi, T. Subroto, M. Conte, K. Pericelous, D. Eskin, P. Prentice, and I. Tzanakis, Light Metals 2020, ed. A. Tomsett (Cham: Springer, 2020), p. 168.

35. A.T. Dinsdale and P.N. Quested, J. Mater. Sci. 39, 7221 (2004).

36. D. Eskin, N. Alba-Baena, T. Pabel, and M. da Silva, Mater. Sci. Technol. 31, 79 (2015).

37. O. Kudryashova, S. Vorozhtsov, A. Khrustalyov, and M. Stepkina, AIP Conf. Proc. 1772, 020013 (2016).

38. I. Tzanakis, G.S.B. Lebon, D.G. Eskin, and K. Pericleous, Light Metals 2016, ed. E. Williams (Hoboken: Wiley, 2016), p. 833 .
39. G.S.B. Lebon, K. Pericleous, I. Tzanakis, and D. Eskin, Int. J. Cast Met. Res. 29, 324 (2016).

40. T. Subroto, D.G. Eskin, C. Beckwith, I. Tzanakis, G. Djambazov, and K. Pericleous, Light Metals 2020, ed. A. Tomsett (Cham: Springer, 2020), p. 981.

41. T. Subroto, D.G. Eskin, I. Tzanakis, G.S.B. Lebon, A. Miranda, and K. Pericleous, IOP Conf. Ser. Mater. Sci. Eng. 529, 012050 (2019).

Publisher's Note Springer Nature remains neutral with regard to jurisdictional claims in published maps and institutional affiliations. 